\title{
O SIGNIFICADO DO CUIDADO DO PACIENTE COM AIDS UMA PERSPECTIVA DE COMPREENSĀO *
}

\author{
Dorotea Erica Dresler ** \\ Magali Roseira Boemer ***
}

\begin{abstract}
RESUMO - Os autores se propõe a desvelar facetas do significado do cuidado ao paciente com AIDS, aos olhos dos funcionários do Serviço de Enfermagem que cuidam do paciente. Para tanto, recorrem a uma metodologia de pesquisa qualitativa - a investigação fenomenológica - que lhes permita o acesso a esse objeto de estudo, à sua essência. Desta forma, são coletados depoimentos de funcionários de uma Clínica de Moléstias Infecto-Contagiosas de um Hospital Geral Escola, mediante a questão orientadora "o que significa para você o cuidado com AIDS ?" Os depoimentos foram analisados segundo suas convergências de acordo com os passos da pesquisa fenomenológica e, a partir delas, foram elaboradas as unidades significativas que expressam a essência do significado desse cuidado. os resultados mostram o desvelamento de facetas importantes ligadas ao cuidado do paciente com AIDS, tais como o risco e o medo que permeiam o cotidiano de trabalho desses funcionários, o desconforto gerado pela necessidade do uso de vários parâmentos para a execução das técnicas, bem como toda a dificuldade que sentem no lidar com paciente percebido por eles como "difícil". Surgem ainda facetas fundamentais verbalizadas por eles como a opção pessoal para prestar o cuidado, associada à necessidade de preparo, valorização e reconhecimento. Na opinião dos autores, o desvelamento dessas facetas se constitui em novos caminhos para a assistência de enfermagem ao paciente com AIDS na medida em que contempla a essência do cuidado aos olhos de quem o presta, em sua situcionalidade.
\end{abstract}

ABSTRACT - The objective of the present study was to clarify the differents aspects of the meaning of care for patients with AIDS as seen by nursing employees who provide this care. The research methodology used has been a qualitative one phenomenologic investigation - that would permit access to this topic of study and to its essence. Thus, statements were obtained from the employees of a Clinic for Infectious - Contagious Diseases of a General Teaching Hospital in response to the following quiding question: "What does it mean to you to care for a patient whith AIDS ? The statements were analyzed according to their convergencies using the steps of phenomenologic research, and the significant units that express the essence of the meaning of this care were elaborated from them. The results led the classification of important aspects related to the care for the patients with AIDS, such as the risk an fear that permeat the daily work routine of these employees, the disconfort generated by the need using several parameters for the execution of the techniques, and the difficulty they experience in dealing with patients that are perceived by them as "difficult" ones. Fundamental aspects have been also verbalized by the employees, such as a personal option to care for these patients, associated with the need for preparation, appreciation and recognition. In the author's opinion, the classification of these aspects opens new means for nursing care to patients with AIDS by contemplating the essence of care as seen by those who provide it, in its situationality.

* Prêmio Wanda de Aguiar Horta - 1 Lugar - 42ㅇ Congresso Brasileiro de Enfermagem - Natal-RN

** Enfermeira Chefe da Unidade de Internação Moléstias Infecto - Contagiosas do Hospital das Clínicas da Faculdades de Medicina de Ribeirão Preto - USP - COREn SP 8486

*** Professor Associado da Escola de Enfermagem de Ribeirão Preto - USP - COREn SP 6331 


\section{INTRODUÇÃO}

O primeiro reconhecimento oficial de uma nova doença foi publicado no "Mortality and Morbidity Weekly Report”, o diário oficial do Center for Disease Control (CDC) do Serviço de Saúde dos Estados Unidos, em 1981, conforme relata PASTERNAK ${ }^{19}$.

Após essa publicação, vários simpósios a respeito do assunto foram realizados e a partir daí foi dado o nome para essa doença: AIDS (Syndrome de Immunodeficience Acquire).

Segundo BOMTEMPO" "AIDS, como pronúncia ou dita de qualquer modo, é um conjunto de letras que no momento vem se tornando bastante familiar e é soprada com muita angústia ... porque mata". AIDS em inglês soa como ajuda, um bom nome para uma doença que certamente ajuda para quem a tem, cuja tradução fonética é "EIDS", no inglês falado nos Estados Unidos, conforme lembra PASTERNAK ${ }^{19}$ e significa a presença de doença indicativa de imunidade celular e a ausência de causas conhecidas de imunodeficiência ou perda de resistência.

Conforme Manual da Secretaria de Saúde - São Paulo**** os mecanismos de transmissão do virus HIV (Human Immunodeficience Virus) responsável pela AIDS são os que dependem do sangue ou derivados e do relacionamento sexual, através do esperma e da secreção vaginal. Outro mecanismo de transmissão refere-se à amamentação de mulher infectada e também à infecção acidental de pessoas por meio de agulhas e seringas que contém o sangue com o HIV, sobretudo em atividades profissionais na área da saúde.

Verifica-se a presença do HIV no sangue, esperma, secreção vaginal, saliva, leite, suor, linfonodos, sistema nervoso central, líquido céfalo-raquidiano, medula óssea e no lavado de secreção bronco-alveolar. Em necrópsias foi encontrado o HIV em vários Grgãos.

Diante desses conhecimentos, é lícito temer que contatos com tais fluídos ou tecidos sejam potencialmente arriscados. Acreditar em provável risco é compreensível, ainda que rigor científico seja indispensável no sentido de provar algo apenas suspeitado.

É importante acrescentar que fômites, convívio social ou em ambientes de trabalho e uso de utensilios pessoais, desde que respeitadas as normas higiênicas fundamentais, não possibilitam infecção pelo HIV.

VERONESI e FOCACCIA ${ }^{21}$ referem que está demonstrado estatísticamente que o profissional de saúde corre o maior risco de contágio que outros profissionais. Felizmente, todavia, o contágio acidental é relativamente raro entre os profissionais de saúde, desde que adotem as recomendações específicas para prevenção de tais acidentes.

LIMA $^{11}$ refere também que um grande problema no tratamento desses enfermos é o que concerme à equipe que tem contato direto com eles, principalmente pessoal paramédico. Relata que às vezes exames como eletrocardiograma e endoscopia deixam de ser realizados devido ao temor em tocar nos pacientes. $\mathrm{Na}$ realidade não está provado que algum trabalhador da área de saúde que lida com esses enfermos tenha contraído a doença por contato, no entanto, deve usar gorro, máscara, luvas, enfim, tomar as devidas precauções.

Esse autor continua relatando a importância do esclarecimento público, principalmente do pessoal de saúde, que se mostra temeroso de lidar com os doentes e que já tem chegado a provocar absenteísmo e mesmo abandono de emptegos em hospitais.

PRATT $^{20}$ relata fatos ocorridos na Inglaterra em 1984, quando houve aumento do número de casos de AIDS, levando os profissionais de saúde e um estado de confusão e temor. Refere também que o cuidado desses pacientes durante as vinte e quatro horas do dia era de responsabilidade preponderante das enfermeiras, que começaram a ficar envolvidas frequentemente pela ansiedade e mesmo hostilidade da equipe subalterna: as funcionárias da limpeza recusavam-se a desinfetar o quarto desses pacientes, as copeiras declinavam-se a servir as bandeijas de refeição, os porteiros negavam-se a colaborar no transporte desses pacientes.

$\mathrm{LACAZ}^{10}$ refere que a AIDS trouxe à tona o medo e o pânico, levando à alterações significativas das interações interpessoais no contex to social em que vivemos. Vem, sobretudo, modificando comportamentos, trazendo à tona preconceitos.

PASTERNAK ${ }^{19}$ relata que a AIDS traz problemas que não são propriamente originais para os profissionais que cuidam de doentes graves; doenças com prognóstico fatal que acaba envolvendo emocionalmente os prestadores de serviços de saúde. Surgiram dificuldades que precisam ser francamente discutidas e, ao lado do tratamento dos problemas emocionais dos pacientes e de suas familias, deveria ser oferecido algum tipo de apoio psicologico ao pessoal médico e de enfermagem que lida com as complicações progressivas do doente com AIDS.

PASTERNAK $^{19}$ ainda refere que a primeira coisa que o paciente com AIDS sente é a perda da liberdade pessoal e a um desaparecimento súbito dos amigos, parentes e dos companheiros. De repente, o doente está s 6 , e seus contatos humanos passam a ser feitos quase exclusivamente com o pessoal que o atende, estreitamento seu mundo.

Esse mundo muito pequeno, centrado no hospital, na doença, nos remédios e nas flutuações de seus sintomas, acaba envolvendo os médicos e a enfermagem, especificamente esta última.

Tudo isso é feito por gente sobrecarregada, com trabalho braçal a ser executado, medicação para ser dada, veias para serem pegas e mil e uma coisas. Não é de admirar que a enfermeira fique exausta na presença desses pacientes, e também que muitas pessoas dessa área peçam para sair dela, decorrido algum tempo. É o que o americano chama de "burned-out", quando a carga emocional torna-se demasiado pesada para o pessoal que atua nessas áreas críticas.

Segundo PASTERNAK ${ }^{19}$ a enfermagem não deveria ficar mais que 2 a 4 anos no atendimento desse tipo de paciente. Além disso, a famnia do pessoal de enfermagem que cuida de pacientes com AIDS tamberm tem seus problemas e temores achando que vão se contaminar.

Das doenças como a AIDS, decorrem atos e comportamentos, fenômenos sociais, medos e idéias que são respostas a esse acaso e que vão levar a um mundo diferente, onde se viverá com a AIDS. $\mathrm{O}$ im-

\footnotetext{
**** Manual - AIDS - Secretaria da Saúde do Estado de São Paulo - Edição pela Federação de Obras Sociais - Hospital das Clf-
} nicas da Faculdade de Medicina - USP - Projeto AIDS/USP, 1988 
portante é não. viver num mundo fechado e mesquinho, só porque existe a AIDS; essa luta deve ser iniciada e levada em frente por todos aqueles que querem viver num mundo para transformá-lo, e nesse sentido a AIDS não e só um problema a ser resolvido por cientistas biológicos num contexto puramente técnico.

PRATT $^{20}$ refere que o inimigo não é somente o vírus da AIDS (HIV), mas igualmente o medo, a ignorância e o preconceito.

As observações desses autores nos remeteram à literatura de enfermagem para apreendermos nessa literatura como os profissionais enfermeiros estão vendo e tratando das questões atinentes à assistência de emfermagem a portadores de AIDS.

MENEGHIN ${ }^{16}$ refere que é importante que o enfermeiro esteja atualizado, acompanhe o desenvolvimento das pesquisas e dessa forma se conscientize sobre suas possibilidades para atender o paciente. Refere-se também à necessidade de conhecimentos sobre a sexualidade humana e a realidade da morte eminente, geralmente cercados de tabus e preconceitos, quando se dispōe a prestar assistência aos aidéticos.

MORIYA e cols ${ }^{17}$, ao abordarem a questão do isolamento em doenças transmissíveis, referem-se que as quatro paredes da unidade de isolamento, as portas sempre fechadas, as janelas teladas e a proibição de sair da unidade, constituiem uma barreira que dificulta a relação social do paciente com o mundo exterior. Também o mesmo ocorre com a Enfermagem, pois ela acaba sendo vista de modo especial, podendo ficar isolada dos demais membros do hospital.

As doenças sexualmente transmissíveis, segundo OLIVEIRA e $\operatorname{cols}^{18}$, trazem consigo um estigma histórico, vinculado à prostituição, à marginalização e doenças originárias do pecado. Estes preconceitos e tabus acarretam sérios problemas psicossociais, levando os indivíduos a se ocultarem, a fim de não serem identificados pela sociedade, nem alvos de curiosidade ou rejeição popular.

BERGAMO e cols ${ }^{2}$ preocupados com a disseminação da AIDS, realizaram um estudo sobre procedimentos técnico-básicos na prevenção da AIDS num centro cirúrgico, concluindo pela importância da conscientização dos profissionais em relação à execução de técnicas preconizadas para prevenção desta doença, em relação a material, ambiente e cuidados com as mãos.

DESSUNT $^{6}$, em estudo sobre percepção de alunos e equipe de enfermagem em relação ao paciente com suspeita ou diagnóstico de AIDS, conclui que os alunos e equipe de enfermagem apresentaram medo, receio, pena, censura (homossexuais e drogados) e insegurança no atendimento aos pacientes com AIDS.

$G^{7}{ }^{7}$ realizou um estudo sobre interação verbal entre a equipe de Enfermagem e pacientes aidéticos, no mesmo local em que estamos realizando o presente trabalho e detectou que o auxiliar de enfermagem foi o elemento da equipe que permaneceu mais tempo junto ao paciente, seguido pela enfermeira e atendente de enfermagem; o auxiliar e a enfermeira dispensaram maior tempo junto aos pacientes em estado regular e/ou grave e o atendente junto aos que se apresentavam num melhor estado.

MACIEL ${ }^{13}$ em estudo sobre proposta da Assistência de Enfermagem realizado entre os enfermeiros frente ao paciente com AIDS, salienta a importân- cia de se buscar diretrizes para a assistência de enfermagem e de estimular a participação científica do enfermeiro junto à equipe multiprofissional e contribuir com uma proposta para a assistência de enfermagem a esses pacientes.

Do levantamento realizado, vemos que a literatura de enfermagem tem tratado pouco do assunto e que são poucas as publicações sobre a assistência de enfermagem específica a portadores de AIDS, confirmando as observaçōes de MENEGHIN ${ }^{16}$.

Assim é que revisamos quatro periódicos de enfermagem (Revista Brasileira de Enfermagem, Revista da Escola de Enfermagem da USP, Revista Gaúcha de Enfermagem e Revista Paulista de Enfermagem) nos anos de 1985 a 1989, bem como um periódico de caráter mais geral (Revista Paulista de Hospital) e um específico (Jornal Brasileiro de Psiquiatria) no mesmo periodico.

Essa revisão nos permitiu localizar um total de oitenta e uma revistas referentes a esses artigos nos últimos cinco anos, onde encontramos apenas nove artigos que tratavam do tema da AIDS sob alguma perspectiva, ou então, de forma mais geral, de doenças transmissíveis ou ainda sexualmente transmissíveis.

Em sete catálogos do CEPEn (Vol. I, II, III, IV,V, VI, e VIII) encontramos a referência de somente um trabalho relacionado à AIDS e Doenças Sexualmente Transmissíveis.

Desta forma, a consulta à literatura, se por um lado não respondeu aos nossos questionamentos, por outro nos animou a prosseguir nesse estudo, na busca de respostas à algumas situações que temos vivenciado.

Enquanto enfermeira-chefe da Unidade de Internação da Clínica de Moléstias Infecto-Contagiosas, temos observado um número crescente e acentuado do número de casos de AIDS que necessitam de internação e sempre em estado grave; surgiram os casos de crianças hemofilicas, os filhos de mães infectadas e os que adquiriram AIDS por transmissão.

Desde fevereiro de 1986 estamos atendendo aos indivíduos portadores de AIDS e, enquanto responsável pela qualidade de assistência de enfermagem prestada aos mesmos, observando o que se passava junto deles e também o que estava acontecendo aos prestadores de serviços (enfermeiros, técnicos de enfermagem, auxiliares de enfermagem e atendentes), temos visto fatos inusitados, tais como:

- Preocupação constante de quanto tempo cada um permanece junto ao paciente;

- Questionamentos feitos por esse pessoal sobre a possibilidade do tratamento do paciente com AIDS ser realizado em seu domicílio;

- Inquietação quando a farnília do paciente o rejeitava, não tendo para onde ir, obrigando-o a ficar hospitalizado;

- Distribuição em rodízio das colheitas de sangue ou punções venosas entre todos; (exceto o atendente, a quem não é atribuída tal função)

- Verbalização de cansaço;

- Pedidos de licenças-saúde e aumento dos acidentes de trabalho;

- Manifestação de satisfação quando permitido um acompanhante junto ao paciente, que colaborasse com os cuidados, desde que seguisse as regras do isolamento. 
Esses fatos nos preocupam quanto à qualidade de assistência que estava sendo of erecida aos portadores de AIDS durante sua internação. Como responsável pelo setor também estávamos vivenciando tais questionamentos, propondo-nos inclusive a entrar no rodízio para divisão das colheitas de sangue e executando tarefas diretas ao lado do paciente, quando já nos encontrávamos dentro da enfermaria.

Procuramos então, além de busca de conhecimentos através de leituras de textos referentes à AIDS, participar de cursos e encontros que pudessem clarear toda essa situação, desta forma foi gratificante para nós participar de um encontro sobre pesquisa qualitativa em enfermagem*, onde vislumbramos o caminho a ser percorrido, buscando novos horizontes.

Pudemos, então, clarear que dado o objetivo de nosso estudo - as pessoas do Serviço de Enfermagem que prestam cuidado ao paciente com AIDS - seria necessário uma condução metodológica que permitisse o acesso a essas pessoas naquilo que representa para elas o cuidado a esse paciente, com toda a gama de sentimentos, emoções, medos e tabus.

Desta forma, a investigação fenomenológica enquanto modalidade da pesquisa qualitativa se nos apresentou como a alternativa metodológica que nos possibilitaria o desvelamento do significado do cuidado ao paciente com AIDS, aos olhos de quem presta esse cuidado - os atendentes, auxiliares, técnicos de enfermagem e enfermeiros - visando apreender a essência desse significado.

\section{2 - METODOLOGIA}

O estudo foi realizado segundo a metodologia de investigação fenomenológica com a finalidade de conhecer o significado do cuidar do paciente com AIDS, aos olhos do pessoal de enfermagem que presta esse cuidado.

Em sua proposta de desvelamento de um fenômeno, o referencial da fenomenologia irá se preocupar com a essência deste fenômeno, naquilo que se mostra como essencial. Desta forma, chegar à essência implica em apontar para aquilo que o fenômeno $e$.

Uma investigação conduzida sob a metodologia fenomenologica ira se preocupar em estudar o fenómeno situado, tal como ele se apresenta aos olhos de quem experiência a situação. Para tanto, a subjetividade $\varepsilon$ fundamental para esse método na medida em que a fenomenologia se preocupa com a ciência do vivido e os significados serấo atribuídos pelo sujeito que vive a experiência.

Sob esta perspectiva, o significado do cuidar com o paciente com AIDS deverá ser buscado nos sujeitos que realizam esse cuidado, ou seja, os funcionários do Serviço de Enfermagem por serem eles os que vivenciam esse cuidar. Através do seu logus, da sua fala $e$ possível chegar ao significado dessa experiência na medida em que a fala revela parte do SER do homem.

Assim para que o fenômeno situado "estar cuidando de um paciente com AIDS", num contexto hospitalar pudesse mostrar-se a nós, se desvelando, era necessário buscar nas falas dos funcionários que dele cuidam, o significado desse experienciar.

Elaboramos então a questão orientadora "O que significa para você o cuidar do paciente com AIDS ?" para ser proposta a cada um dos funcionários de forma a lhe possibilitar seu depoimento.

\section{O Local e os Sugeitos da Pesquisa}

O estudo foi planejado pelas autoras para ser realizado na Unidade de Internação de Moléstias Infecto-Contagiosas do Hospital das Clínicas da Faculdade de Medicina de Ribeirão Preto - USP. Após encaminhamento à Comissão de Ética do hospital, o projeto mereceu aprovação.

Os depoimentos foram coletados no período de 02 de março a 09 de abril de 1990 e abrangeu todos os funcionários que atuam nessa Unidade (enfermeiros, técnicos, auxiliares e atendentes de enfermagem) bem como enfermeiras e diretora de serviço de Clínica Médica que, como já expusemos, assumem também funções nessa Unidade.

\section{Coleta de Depoimentos}

Enquanto enfermeira-chefe da Unidade, comunicamos durante as passagens de plantão nossa intenção de realizar um estudo para o qual seria importante a colaboração de todos.

Dissemos que o objetivo era conhecer como estavam vendo o cuidado ao paciente com AIDS, o significado para eles, com vistas à compreensão dessa visão. Explicamos também que a participação voluntária, que o depoimento teria caráter confidencial, não haveria necessidade de identificação e absolutamente não seria usado julgamento ou censura.

Solicitamos ainda que aqueles que se dispusessem em participar que declarassem, por escrito, que o estavam fazendo de livre e espontânea vontade, atendendo assim à recomendação que nos foi feita pela Comissão de Ética do Hospital.

Todos os funcionários se dispuseram em colaborar com entusiasmo e assim, mediante encontros individuais, fomos orientando para que dessem o seu depoimento.

Foi entregue uma folha de papel sulfite onde havia a questão orientadora.

"O que significa para você o cuidar de um paciente com AIDS ?”

Como as atividades são frequentemente intensas na área, esperávamos um momento de pausa entre essas atividades, falávamos com cada um e entregávamos a folha de papel onde ele iria responder, podendo levar para casa mas com a orientação que nos entregasse em outro momento.

Não houve recusa de nenhum dos elementos, apenas deixou de participar quem estava de férias, licença-saúde e licença por acidente de trabalho.

Foram coletados trinta e cinco depoimentos.

\section{Leitura e Análise dos Depoimentos}

Buscamos na leitura dos depoimentos as suas convergências, ao invariante, ou seja, aquilo que se apresentava com a característica de repetitividade. Esse invariante está apontando para aquilo que $\epsilon$, ou seja, a essência no pensar fenomenológico.

Essa leitura com visitas à apreensão das convergências e elaboração das unidadres significativas

* I Encontro Interamericano de Pesquisa Qualitativa em Enfermagem, São Paulo, 22 a 26 de fevereiro de 1988 
foi realizada segundo os passos da metologia fenomenologica conforme preconizam MARTINS \& BICUDO $^{14}$ e MARTINS e cols ${ }^{15}$;

-O pesquisador detém-se na leitura da descrição do princípio ao fim sem buscar ainda qualquer interpretação ou identificação de qualquer atributo ou elemento, a fim de chegar a um sentido geral do que está escrito;

- No momento em que um sentido foi obtido, o pesquisador volta ao início e lê novamente o texto, agora tentando através das convergências apreender unidades de significado, dentro da sua perspectiva e focalizando o fenômeno que está sendo pesquisado;

- Após obter unidades de significado, o pesquisador percorre todas as unidades identificadas e expressa o significado contido nelas; isto $\varepsilon$ particularmente verdadeiro para as unidades que são mais reveladores do fenômeno considerado;

- Finalmente o pesquisador sintetiza todas as unidades de significado para chegar a uma estrutura do fenômeno.

Desta forma, a análise dos depoimentos dos funcionários da clínica do estudo nos possibilitou chegar às unidades que expressam a essência do significado do cuidar do paciente com AIDS.

\section{3 - APRESENTAÇÃO E ANÁLISE DOS RESULTADOS}

A análise dos depoimentos de trinta e cinco funcionários sobre o significado do cuidar do paciente com AIDS, nos permite observar que há convergências entre seus conteúdos, ou se ja, aspectos considerados relevantes por eles no que se refere a esse cuidado. Essas convergências possibilitam-nos alguns desvelamento desse significado de forma que podemos, a partir de suas falas compreender o seu cotidiano de trabalho.

Desta forma, a análise compreensiva dos depoimentos nos revela que, aos olhos dos funcionários, o cuidado do paciente com AIDS se mostra como:

\section{- Uma atividade de Enfermagem que deve ser feita com muito rigor, cuidado e atençāo onde qualquer descuido pode levar a pessoa a se contaminar e se tornar um doente tambem.}

As falas dos funcionários evidenciam de forma marcante a sua percepção de que correm risco ao prestar o cuidado:

"Corro risco de adquirir essa doença"

"Toda atenção ê redobrada"

"O risco de contaminação existe em cada movimento dos profissionais"

"Devemos nos precaver para evitar uma possível contaminação"

"Corro o risco de me contaminar acidentalmente"

"Estamos sujeitos a qualquer tipo de risco"

"O fantasma da contaminação é muito grande"

Um olhar atento para as atividades desempenhadas por esses profissionais nos permite visualizar a razão de suas percepçōes de que correm risco.
Quando temos ciência, na clínica, que o vírus HIV foi detectado nos vários fluídos orgânicos, vemos que o manuseio com esses fluídos 6 frequente, desde muitas punções venosas para administração de medicamentos (os antibióticos não podem ser feitos na mesma hora e às vezes nem no mesmo local) até colheitas de sangue, liquor, urina, fezes, escarro, punções de medula, biopsia.

Esse manuseio acontece também na troca de fraldas e na desinfecção de urina e fezes pois geralmente o paciente apresenta diarréia.

Desde que os aidéticos são atendidos neste local, observamos aumento da incidência de acidentes de trabalho por motivos insignificantes, mas que, apos o comunicado de acidente de trabalho, os profissionais foram seguidos no mesmo ambulatório que os aidéticos, havendo rigor quanto a data das colheitas para a pesquisa de anti-HIV.

Todo o grupo tomou conhecimento desses fatos para se tomar medidas no sentido de se evitar tais acidentes. Esses, geraram um clima de ansiedade, pois, alem de os profissionais de saúde que lidam com os aidéticos serem considerados como grupo de risco, havia a incerteza e expectativa de o exame dar positivo em qualquer momento das colheitas.

No início, o resultado do exame para anti-HIV era impresso como "positivo" ou "negativo". Posteriormente, o resultado era impresso em níveis de titulagem e níveis de "cut-off". Dessa forma, aumentou a intranquilidade quando o profissional acidentado procurava ver o resultado e não entendia, julgando que se estava escondendo algo dele, sendo difícil aceitar o esclarecimento sobre esta forma de resultado.

Tal clima fez com que alguns profissionais escondessem ou não fizessem o comunicado oficial de acidente de trabalho sofriam uma picada com agulha contaminada para evitar tais dissabores mas, era certo que eles faziam a desinfecção do local corretamente.

Outro dado expressivo de que o profissional sente que corre o risco e teme o contágio surge sob a forma de crítica à equipe médica no que se refere ao diagnóstico imediato, solicitando a pesquisa de antiHIV:

"O que mais me preocupa, no entanto, $\epsilon$ o comportamento dos médicos, que primeiro pedem todos os tipos de exames para depois pedir o HIV".

“. . . S6 liberando o isolamento quando tiver certeza do resultado negativo, neste caso outros pacientes que ficam juntos na mesma enfermaria também estão correndo risco"

"os médicos internam o paciente e demora para colher o anti-HIV; primeiro colhem todos os tipos de sangue, menos o que teria que ser primeiro lugar: HIV"

A solicitação do anti-HIV nos vários setorés do hospital deverá ter o aval do docente da Disciplina de Moléstias Infecciosas, para que o Banco de Sangue informe o resultado; porém, os médicos residentes do M.I. podem solicitar, sem ser necessária tal permissão. Observamos que quando um dos funcionários percebe características pertinentes aos grupos de iiscos e, mesmo sem o diagnóstico de AIDS, nos alerta sobre o fato para que sirvamos de intermediário com a equipe 
médica.

Outro fato interessante $\varepsilon$ que, mesmo quando ela tem a certeza de que o paciente pertence ao grupo de risco e com o resultado negativo de anti-HIV, as precauções com sangue e flứdos orgânicos são feitas.

Observamos ainda que a apreensão dos profissionais em relação ao risco de contaminação se configura num futuro proximo ou remoto, pois os estudos sobre o tempo de soro-conversão não permitem ainda a confirmação diagnóstica imediata.

Desta forma, a contaminação enquanto possibilidade concreta de sua existência emerge de força muito presente em seus depoimentos, evindenciando um cotidiano de trabalho permeado por essa incerteza. Não se trata mais de uma possibilidade que se apresenta a qualquer pessoa, mas sim a SUA pessoa, pois dada a SUA situação de trabalho, ele é mais exposto à doença.

O desvelar dessa faceta remete-nos a refletir sobre um cotidiano de trabalho que precisa ser compreendido numa perspectiva administrativa.

Una atividade que se reveste de um medo muito relacionado ao risco da contaminaçāo:

Paralelamente ao risco da contaminação o seu cotidiano de trabalho se mostra permeado pelo medo como mostram as suas falas:

"Medo da morte"

"Não sei bem ao certo se é ter medo de se contaminar ou se $\varepsilon$ medo do proprio paciente"

"Tenho medo"

"Não teria estrutura para erradicar o meu medo"

"Sinto medo de ser contaminado"

"As vezes sinto receio"

"Me sinto temeroso, com medo de cuidar do paciente"

Apreendemos nas falas dos profissionais que esse cotidiano permeado pelo risco 6 gerador de uma sensação de medo. Esse medo nem sempre surge claramente definido ou às vezes explicita o medo maior "medo da morte".

É interessante observar que em nossa vivência nessa Unidade, no exerćcio de nossas funçōes, este sentimento de medo não se mostrava tão claro para nós. Acreditávamos que com as nossas orientações sobre formas de proteção que poderiam lançar mão, sobre meios de transmissão, procurando sempre material necessário e, sobretudo, com a nossa postura pessoal de tranquilidade em relação aos riscos, não houvesse medo na intensidade em que pudemos perceber nos depoimentos.

Julgávamos também que a forma como vínhamos distribuindo as diferentes tarefas pertinentes à assistência de enfermagem de modo a possibilitar um rodízio de pessoal nos cuidados considerados mais diretos e a implementação de uma filosofia de trabalho em equipe de forma efetiva, pudesse estar amenizando o medo da exposição à doença e, consequentemente, diminuindo-o.

Entretanto, os depoimentos veêm mostrar que is-

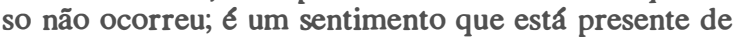
forma clara ou mais velada.

No cotidiano de trabalho na Unidade não temos observado recusas em assistir o doente por parte des- ses profissionais, apesar desse sentimento de medo que verbalizam. Isto nos leva a pensar que aprenderam a conviver com o medo e o incorporaram ao modo como se situam no mundo da Unidade.

Desta forma, o medo passa a fazer parte do seu mundo de trabalho e poderia estar abrindo, a nosso ver, um caminho para a angústia. Suas expressões de medo contém, na realidade, a incerteza de sua sobrevivência e, nesse sentido, está em jogo o seu SER.

No pensar de HEIDEGGER ${ }^{8}$, a angústia surge da características fundamental do homem como o ente cujo ser se orienta pela preocupação com sua própria existência. É esse modo universal que o separa de todos os demais entes do Universo. A angústia, diz o filbsofo, não pode ser enfrentada, por um ser finito, por mais do que um breve instante, tal o horror e o desespero que podem se apoderar dele.

Do exposto, parece-nos evidente que tal cotidiano de trabalho precisa merecer mais atenção dos setores administrativos, de modo que o conviver com esse medo possa ser trabalhando de forma a proporcionar condições mais humanas de trabalho.

Una atividade onde o doente a ser cuidado apresenta-se como difícil

Vejamos algumas falas que nos possibilitam essa apreensão:

"É difícil lidar com ele"

"São inescrupulosos"

"Quase todos tornam-se agressivos"

"Apenas exige"

"Pacientes tão carentes"

'Pacientes com o quadro psicologico muito alterado"

"Durante a internação são agressivos, rebeldes, angustiados, deprimidos, exigentes"

"Nẫo aceitas cuidados e, às vezes, agridem a enfermagem com palavrões"

"Paciente carente e apavorado"

"Paciente não confia no tratamento, além de transmitir toda a sua ansiedade e depressão"

"Eles não gostam de ficar sozinhos, chamam toda hora, muitas das vezes sem necessidade"

"Reconhece pouco"

"Estado geral bastante debilitado"

"O que passa pela cabeça deles não sabemos"

"Difíceis de aceitar a doença"

"Fazem perguntas que eu não posso responder"

As qualificações citadas em relação aos aidéticos (inescrupulosos, agressivos, carentes, rebeldes, angustiados, deprimidos, exigentes) nos dizem o quanto é difícil compreendê-los.

Há situações em que o viciado em drogas endovenosas apresenta-se na sua internação sem rede venosa acessível, necessária para realização dos exames de sangue e tratamento, já que ele sempre usou essa via para injeção de drogas; ocorre, então que nos momentos de se fazer a punção o paciente fica escolhendo o local, ensinando-nos como executar a técnica. essa atitude do paciente vem chocar a equipe de enfermagem na medida em que entendem que ele questiona a propria capacidade profissional dos seus integrantes.

Quando percebemos a agressão verbal do doente frente ao profissional, chegamos a não suportar tal agressividade, pois no nosso entender estamos alí para 
ajudá-lo e não para prejudicá-lo. Em um primeiro momento, a nossa reação seria revidar a tudo quanto ele nos of ende, mas isso fica somente na intenção, pois imediatamente vem à tona o ideal de enfermagem; prestação de ajuda.

Dessa forma, tentando compreendê-los procuramos transcender a dimensão do tratamento físico que está agredindo a sua integridade física, que é o que ele quer preservar naquele momento.

Temos observado também que o tratamento endovenoso por exemplo, com anfotericina-B se reveste de uma dificuldade particular para o doente que o recebe, dadas as reaçôes orgânicas que 0 acometem, tais como aumento da febre e tremores, levando-o, muitas vezes, a não suportar o tratamento. Assim, é comum que o doente solicite alta, implicando numa postura de abandono do tratamento.

Essas situações são vivençiadas pela equipe de enfermagem, que, muitas vezes, tem dificuldade por não saber do que fazer com o doente nessas circunstâncias, gerando um clima de insegurança que se instala para ambos - paciente e enfermagem.

Nesse sentido, os elementos da enfermagem se deparam com situações de conflito onde emergem facetas ligada

à sua capacidade profissional para seleção do local de aplicação da medicação, capacidade essa que, como já referimos, é questionada pelo paciente, e ãs dificuldades crescentes que essas pessoas vão tendo para selecionar uma veia, dado os danos que a própria medicação gera na rede venosa do doente. A essas, acresce-se o conflito diante da necessidade de executar o procedimento prescrito pelo médico e compreender o doente na sua percepção dos ef eitos desagradáveis da medicação e sua intenção de abandono do tratamento.

Como podemos ver, não se trata de uma tarefa fácil para a enfermagem, considerando que $o$ ato de compreender o ser humano não se aprende em manuais ou compêndios, mas sim envolve o vivenciar de situações onde o outro se apresenta carecendo de compreensão. É o cotidiano do trabalho com esses doentes que revela aos profissionais a percepção do sofrimento humano e os recursos pessoais para compartilhar com ele os momentos permeados por esses conflitos.

Nesse sentido os depoimentos revelam que a possibilidade de compreençã̃p do paciente com AIDS se apresenta interligada ao grupo de risco ao qual o paciente pertence. Desta forma, em suas falas emerge um julgamento concernente a história de vida do paciente. Vejamos algumas falas nesse sentido:

"O homossexual é o que é mais acessível"

"O hemofilico: o mais apático e um pouco revoltado"

"O viciado é o paciente mais diff́cil de se chegar"

"Sinto pena das crianças, porque são vítimas da fatalidade"

“Os demais aidédicos, são consequências de seus próprios atos"

"Os homossexuais, drogados, presidiários são mais dependentes"

"Os hemofllicos, crianças, sinto também pena"

"As crianças são a parte que me dói mais"

"Não re jeito os hemofllicos"

O que se revela para nós é que os funcionários percebem o paciente como pertencente a um grupo de risco, julgam a sua forma de vida anterior, relacionam o grupo de risco a determinado comportamento e têm consciência da discriminação social e familiar que cerca o paciente.

Ao lado dessa percepção, não se observa interferência desses fatores no cuidado ao paciente mas sim, na sua forma de compreenção, na forma como pode utilizar seus recursos pessoais para compreender.

Naturalmente que podemos empreender esforços na busca de subsídios que nos auxiliem no fortalecimento desses recursos pessoais, pois, como refere DANIEL $^{5}$, saber como conseguir que os outros façam aquilo que desejamos é uma "arte" que pode ser desenvolvida primeiramente pela consciência de se precisar melhorar, depois pela prática de regras de comunicação positiva e pelo uso de atitudes favoráveis de relacionamento.

Temos, enquanto enfermeira responsável pela chefia dessa Unidade, procurado formas de atenuar esse clima de trabalho que se apresenta desfavorável aos profissionais de enfermagem.Dessa forma, por solicitação nossa, o Setor Administrativo do hospital encaminhou á Unidade duas médicas psiquiátricas que, num exercício profissional voluntário, realizavam atendimento dos paciente e dos funcionários da enfermagem.

Entretanto, tal iniciativa não se constituiu em melhores perspectivas para a unidade, pois as inúmeras tarefas a serem desenvolvidas pela enfermagem não lhe possibilitavam disponibilidade de tempo para receber a assistência de apoio no tempo em que esses profissionais permaneciam na clínica.

Posteriormente, houve a contratação de um médico psiquiatra para exercer seu trabalho de maneira formal na Unidade, envolvendo pacientes e funcionários. Da mesma forma, face ao grande número de tarefas tem havido dificuldades para a enfermagem receber 0 apoio de forma efetiva.

Nesse sentido vemos que há um longo caminho a ser percorrido na busca de formas de sistematizar a assistência de enfermagem calcada em outros modelos que não a execução de tarefas, de forma a proporcionar ao pessoal de enfermagem a possibilidade de procurar apoio e, portanto, melhor potencial para relacionamento com o doente.

\section{- Uma atividade que gera desconforto ao pro- fissional, dada a especificidade das técnicas:}

A especificidade das técnicas a serem desenvolvidas durante o cuidado ao paciente com AIDS, é percebida pelos funcionários como geradora de grande desconforto físico:

"Causa incômodo devido ao calor e ao tempo que se gasta para se parametrar"

"Já entra no quarto sabendo que tem que colocar toda a roupa, sem contar o calor; a máscara é horrível"

"Não vê a hora de sair do quarto e se ver livre"

"Não suportando ficar escalado na mesma enfermaria por-dias seguidos"

"Fica-se muito tempo dentro da en? meira, isto abala muito psicologicamente"

"Lá dentro o calor é insuportável, senti- 
mos o suor escorrer da cabeça aos pés"

"Acho desgastante ficar dentro da enfermaria devido aos cuidados que se processa ao entrar e atender"

"Os cuidados que se prologam por duas ou mais horas, é bastante cansativo"

Os depoimentos expressam o desconforto que o pessoal de enfermagem sente quando do cuidado com o paciente com AIDS. Apesar das técnicas serem rotineiras para o serviço de enfermagem de modo geral, elas se revestem de uma especificidade particular nesse cuidado, dado o risco de transmissibilidade. Desta forma, uma higiene oral, um auxillio para alimentação ou mesmo a verificação de uma diurese assumem características muito próprias nessa clínica.

Percebe-se nos depoimentos que esse desconforto é percebido por eles interligado ao tempo requerido para se paramentarem e se desparamentarem para a execução das técnicas. Há cuidados especiais a serem tomados com cada paramento, por exemplo: o grupo e a máscara devem ser destinados ao lixo do quarto, a luva quando livre de sangue deverá ir para um galheteiro especial e quando com sangue deverá ir para o lixo e assim por diante.

Todos esses paramentos levam a uma sensação de calor, agravada pelo clima naturalmente quente da cidade e que tamberm gera grande desconforto para o pessoal.

Temos procurado no nosso cotidiano, ao fazer a escala diária, determinar para cada profissional o cuidado a um s 6 paciente com AIDS e tamberm a pacientes de outras enfermarias que não aidéticos, em rodízio de dias, numa tentativa de atenuar todo esse desconforto que os relatos expressam. Mas nem sempre isto é possível devido ao número reduzido de pessoal e também à necessidade do aidético do sexo masculino, por exemplo, receber cuidados de um profissional do mesmo sexo; então, muitas vezes é sempre o mesmo profissional que está a cuidar do mesmo paciente.

Durante este tempo, os demais pacientes sob sua responsabilidade não entendem a demora em serem atendidos: além do mais, torna-se-ia necessário um profissional que seja "circulante" para atender os colegas dentro das enfermarias; mas, como o número de pessoal que temos, isto não é possível.

Dadas as características de transmissibilidade envolvidas, caberá ao pessoal de enfermagem executar as tarefas com todo os cuidados inerentes a elas, apesar do desconforto que sente, pois esses cuidados representam, fundamentalmente, a sua proteção e do paciente.

Parece-nos entretanto que algumas medidas administrativas seriam passíveis de serem tomadas e que implicariam em melhores condiçõe de trabalho.

Percebemos que o desconforto pelos paramentos, pelo tempo excessivo em estar se paramentando, em estar prestando cuidados, seria amenizado se estivessemos sob ar condicionado. Desta forma, o paciente também seria beneficiado, já que ele apresenta febre constante, sudorese intensa e, na maioria das vezes, ele permanece com pouca roupa, inibindo o profissional.

São soluçōes possíveis mas que dependem de decisões a nível administrativo que, por vezes, retardam ou postergam medidas que podem representar melhores condições para os funcionários. Parece-nos claro que, num cotidiano onde essencialmente estão presentes o risco, o medo e a dificuldade em interagir com o paciente dadas as suas características, conforme mostram os depoimentos, o fator conforto físico seria o menos diff́cil de ser conseguido, possibilitando condições mais humanas de trabalho.

\section{Uma atividade para a qual a possibilidade de} opção pessoal e fundamental

os depoimentos expressam com clareza que esses elementos da equipe de enfermagem se ressentem por não terem podido opinar quanto a sua disponibilidade em cuidar do paciente com AIDS.

Como já foi exposto, os pacientes com AIDS são internados na Clínica de Moléstias Infecto-Contagiosas, local onde outros pacientes, portadores de outras moléstias, são internados. Esses funcionários, por estarem lotados nessa Clínica, acabam por assumir esse cuidado específico ao paciente aidético. Desta forma, percebem que essa doença surgiu em seu mundo de trabalho e com ela o paciente a ser por eles cuidado de forma tão particular, marcante e estressante.

As suas falas dizem respeito ao seu sentimento de que entendem o cuidado a esse paciente como carente de uma disponibilidade pessoal para o "cuidar":

". . . embora, não sinta muito desejo de cuidar ..."

"Procuro dar tudo de mim, por ela (a criança) sofro muito ...."

"Pois como somos obrigados a lidar com esse tipo de paciente"

"Todas as vezes que cuidei de pacientes com AIDS, não gostei"

"Vou pedir transferéncia"

"Não me recuso a dar-lhe cuidados, s6 não consigo dar-me por inteiro"

"Se fósse para cuidar apenas de paciente aidético eu me recusaria, pois não teria estrutura suficiente"

Outros depoimentos fazem observações relevantes em relação ao pessoal que lida com os aidéticos, evidenciando que além da disponibilidade pessoal, percebem que um preparo se faz necessário. Isto é percebido por eles como essencial e alguns depoimentos nos permitem essa análise:

"Cuidado tem que ser dado por pessoas que estejam física e mentalmente sã para transmitir a este paciente toda a tranquilidade e confiaça de que ele tanto precisa"

"Precisamos de mais apoio, que noseas autoñidades da saúde evitem que isso cresça tanto"

"Estar preparado espiritual e psicologicamente"

"Deveriam estar sempre fazendo reuniōes com psicologos ... Deveriam ser uma pessoa especial, abnegada, pacienciosa"

Ainda observamos referências à necessidade de uma área específica no hospital que pudesse obrigar esses pacientes de forma a serem atendidos por equipe específica e preparada. O que podemos perceber, portanto, éque um requisito de especificidade emerge de forma muito presente nos depoimentos e no qual está contida a questão da sua opção para o cuidar. 
"Se o pessoal pudesse uma área para paciente com AIDS eu estaria disposto a cuidar, desde que fosse of erecido toda a segurança e condições de pessoal"

"Deveria haver uma área específica para este tipo de paciente, pois haveria maiores condições de aperfeiçoamento de pessoal"

"Talvez se fosse uma clínica s6 para eles, que tivessem uma sala para se reunirem e trocar idéias, quem sabe fossem menos rebeldes"

Os depoimentos mostram ainda que a seus olhos, essa atividade é carente de valorização pelas Instituições de Saúde, carência essa que se expressa na baixa remuneração por seu trabalho:

"Angariar recursos maiores, pois afinal de contas você não pode exigir que pessoas ponham em risco sua propria vida para serem mal remunerados"

"Os funcionários precisam de mais conhecimentos e apoio"

"Que sejamos reconhecidos monetariamente"

"Qual a nossa garantia"? perguntam os funcionários? Por quanto tempo sobreviveremos a este desafio?

A leitura desses depoimentos nos remete novamente às várias tentativas que fizemos para que algumas medidas administrativas fossem tomadas no sentido de melhorar as condições de nosso trabalho.

Assim é que solicitamos através de um abaixo assinado, ao Serviço de Nutrição e Dietética, lanche reforçado, porém, não tivemos resultados. Solicitamos também junto à Justiça do Trabalho, a remuneração semelhante ao do pessoal do Hospital Emílio Ribas, de São Paulo e não tivemos resultado.

Solicitamos ainda através de outro abaixo assinado à administração do Hospital, mais um talão de vale-refeição e aumento da nossa taxa de insalubridade e mais uma vez não tivemos resultado.

Entretanto vemos com esse estudo, que não podemos desanimar e que novas tentativas deverão ser feitas para sensibilização dos setores administrativos do hospital de forma que esse pessoal possa ser contemplado em sua situacionalidade de risco e de incerteza.

- Um cuidado que se distingue dos demais face à complexidade psicologica do paciente que o recebe

$O$ pessoal de enfermagem expressa em sua fala que o cuidado ao paciente com AIDS se mostra a eles de forma bastante semelhante aos cuidados que prestam a outros pacientes dependentes ou parcialmente dependentes. Porém percebem que a distinção reside naquilo que denominam "parte psicologica do paciente". No seu entender esses pacientes apresentam comportamentos que requerem mais atenção e compreenão face à gravidade de sua situação, onde uma internação é percebida por eles como "o começo do fim".

As falas nos mostram que os funcionários identificam "os problemas psicológicos" geralmente apresentados por esse paciente e, principalmente, percebem que a assistência psicologica é fundamental.

"É satisfazer suas necessidades fisiologi- cas e psicol6gicas"

"Requerer maior atenção para o seu estado físico e principalmente para seu estado psicologico"

"Paciente com menos resistência física e as vezes, mental"

"Fragilidade emocional do aidético"

"Necessita de cuidados intensivos tanto

na parte física como psicologica"

Observamos que o paciente com AIDS fez com que estes profissionais fizessem a associação mente/corpo e a equipe de enfermagem nesta unidade, tem se voltado para o paciente como um SER TOTAL e na medida do possível tem procurado meios para assistí-lo como um TODO, atingindo tanto o "físico", como o psicologico".

Pelos depoimentos vemos a forma como buscam tornar isto possível:

"Cuido deles com mais carinho, sofro junto com eles"

"Dando valor maior ao diálogo"

"Faço o possível para que o paciente seja bem cuidado e tenha todo o conforto"

"Com carinho e compreensão"

"E é na enfermagem que eles mais se apegam"

"Procurar aliviar suas dores, dar apoio, ficar ao seu lado quando possível"

"Desabafa conversando com a enfermagem"

"Tento com o diálogo dar solidariedade a esses pacientes"

"Uma psicologia mais apurada para fazêlos compreender o porque de alguns cuidados"

Vemos portanto, que ao lado das atividades físicas, o diálogo, o "desaforo" está sempre presente nesse cotidiano de assistência e que tentar identificar o problema do paciente é difícil, mas não impossível. Essa postura possibilita um relacionamento ef etivo entre o ser assistido e o ser que assiste, de forma que o doente confia em quem está ao seu lado, desabafando, enfim.

Observamos também que o doente "desabafa" quando ele tem a percepção de alguém disposto a ouví-lo e interessado em compreendê-lo em sua situação de doente.

A enfermagem moderna com o avanço técnicocientífico tem sofrido um processo de fragmentação do objeto a ser cuidado, de modo a facilitar as tarefas e aumentar a produção do trabalho da enfermagem. Paralelamente vemos a própria medicina dicotomizando o indivíduo, formando cada vez mais especialistas, dentro de especialidades.

DANIEL $^{5}$ nos alerta para o fato que na prática tem-se feito dicotomia entre o somético e o espiritual e por vezes nem os aspectos de apoio psicologico são associados ao tratamento somático.

"O homem estará negando a realização total de sua potencialidade como ser sensível, enquanto persistir a dicotomia entre o interno e o externo, entre a mente e o corpo", nos relata também LOWEN ${ }^{12}$.

Esse desafio à assistência de enfermagem, representado pela AIDS, traz à tona a necessidade de repensarmos a visão do homem a quem o cuidado de enfermagem é dirigido, entendido não como objeto de 
nosso cuidado mas sim como seu sujeito e con-determinador asseveram BOEMER $\mathrm{col}^{3}$.

A enfermagem pode, no seu ato de cuidar, estar considerando o doente no seu "sendo doente" e compartilhar com ele, através da compreensão, os momentos permeados pela angústia e sofrimento. Temos visto ser isso possível para os funcionários ainda que sob um cotidiano que se lhes apresenta com muitas dificuldades.

\section{CONSIDERAÇÕES FINAIS}

Em nossa proposta de compreensão do significado do cuidado de enfermagem ao paciente com AIDS, aos olhos de quem presta esse cuidado, percorremos uma trajetória metodologica que nos permitiu o desvelamento de algumas facetas desse cuidar.

Estar cuidando do paciente com AIDS é visto pelos funcionários como uma atividade onde o risco emerge de forma muito presente, forte e ameaçadora e esse risco existe em cada movimento, em cada ato de cuidar.

$\mathrm{Na}$ execução das atividades pertinentes à assitência de enfermagem esse risco se lhes apresenta como um "fantasma" cuja presença não se anula apesar do rigor das tếcnicas para prevenção da contaminação. Por outro lado, esse mesmo rigor que lhes proporciona proteção do risco é gerador de grande desconforto físico dado o tempo requerido para vestir e desvestir os paramentos usados na unidade, de forma particular para o cuidado ao paciente com AIDS. Ao fator tempo, acresce-se o desconforto pelo calor exacerbado pelos paramentos já referidos.

Ao lado dessa faceta de risco e em decorrência dele, o medo também emerge em suas falas expressando que ele faz parte do seu mundo de trabalho na medida em que eles se vêem ameaçados em sua integridade. Sua perspectiva futura afirma BEANI ${ }^{1}$ a possibilidade de vir-a-ser um doente também.

Revelam ainda em suas falas que o grupo de reisco a que pertence o paciente é um fator que não está alheio ao cuidado, e que a possibilidade de compreenderem o paciente se apresenta interligada a esse grupo. Desta forma, suas falas expressam um julgamento concernente à história de vida do paciente e são conscientes da discriminação social e familiar que o cerca.

\section{REFERÊNCIAS BIBLIOGRÁFICAS}

1 BEAINI, Г.C. A escuta do silêncio uon estudo sobre a linguagem no pensamento de Heidegger. São Paulo: Cortez, 1981.

2 BERGAMO, M.; MARCELINO, K. ; GARRIDO, L.S. Procedimentos TÉcnicos Básicos na prevenção da "AIDS" num Centro Cirúrgico de grande porte. Rev. Bras. Enf., Brasflia, 41(2), 155-160, Abril/Junho, 1988.

3 BOEMER, M.R. e cols. A quem of erecemos o cuidado de Enfermagem - Uma visão fenomenológica, In: I Seminário Nacional - o perfil e a competência do enfermeiro - ANAIS, Brasf́lia, Secretaria da Saúde - Fundação Hospitalar do Distrito Federal, 28 de setembro a 2 de outubro, 95-103p., 1987 (publicado em 1989).

4 BONTEMPO, M. "AIDS" - Esclarecimento global e uma abordagem alternativa", São Paulo, 158p.
Desvelar essa questão - a intensidade desse medo parece-nos fundamental no exercício de nossa função de chefia, pois, embora não o ignorássemos, não o sabíamos em níveis tão altos e certamente teremos que estar atentas na busca de caminhos que possam trabalhar esse sentimento no cotidiano da clínica.

Vemos também que percepção que os funcionários têm do paciente com AIDS como "difícil" advêm do seu convívio com ele e das dificuldades que enfrentam nesse lidar. Expressam tamberm que a "parte psicol6gica" representa uma dimensão especial do cuidado e, em suas verbalizações, o termo "difícil" já se apresenta interligado à uma observação de agressividade, exigência, carência, rebeldia, angústia, depressão, agressão, ansiedade.

Sem dúvida que lidar com todos esses sentimentos requer preparo e essa necessidade é sentida por eles. Além do preparo, demonstram ainda nos depoimentos, que conhecem formas de transformar essas condições e sugerem área física específica, pessoal específico e equipe multidisciplinar que, mutuamente, se auxilie nesse cuidar, numa filosofia de trabalho que contemple a ambos - o paciente e os prestadores de cuidado - em suas situacionalidades.

Há de se considerar ainda que as falas dos funcionários nos remetem à questão da opção pessoal para o cuidado. Há muitas convergências nesse sentido e elas expressam com clareza que essa é uma faceta que se lhes apresenta como fundamental.

Poder optar por prestar o cuidado ao paciente com AIDS significa, a nosso ver, que vêm uma especificidade nesse cuidar e que essa especificidade requer opção, preparo, valorização e reconhecimento. São esses os caminhos que podem levar a novos horizontes para uma sistematização de assistência de enfermagem ao doente portador de AIDS, sistematização essa que contemple o paciente e o funcionário em sua dimensão existencial, resgatando a pessoa viva existente em cada um e expressa na forma em que se percebem mutuamente no mundo do hospital.

De todo o exposto parece-nos clara a necessidade de mais estudos que, ao desvelarem outras facetas ligadas ao doente, à familia e às instituições de saúde, possam se constituir em novos horizontes de compreensão para a assistência ao paciente com AIDS, sob a perspectiva do cuidar.

5 DANIEL, L.F. A enfermagem planejada. São Paulo, EPU, 133p. 1981.

6 DESSUN TI, E.M. Percepção de discentes e equipe de enfermagem em relação ao paciente com suspeita ou diagnóstico de AIDS, Rev. Gaúcha de Enfermagem, Porto Alegre, 10(1): 45-51, janeiro de 1989.

7 GIR, E. Interação verbal entre a equipe de enfermagem e pacientes aidéticos. Dissertação de Mestrado, EERP-USP, Ribeirão Preto, 1988, 210p.

8 HEIDEGGER, M. El ser y el tiempo. Tradução J. Gaos. México, Fondo de Cultura. 1967.

9 KUBLER - ROSS, E. AIDS - $O$ desafio final, Editora BestSeller, São Paulo, 1967. 
10 LACAZ, C.S. AIDS: Doutrina, aspectos iatrofilos 6 ficos, infecçōes oportunistas associadas. São Paulo: Salvador, $124 \mathrm{p} .1985$.

11 LIMA, M.B.C. AIDS/SIDA - Rio de Janeiro: Medsi, 156p. 1986.

12 LOWEN, A. $O$ corpo em depressão, as bases biológicas da fł e da realidade, São Paulo: Summers, 220p. 1972.

13 MACIEL, P.M.A. Os enfermeiros frente ao paciente com Sindrome de Imunodeficiência Adquirida (SIDA-AIDS), uma proposta de assistência de enfermagem. Rio de Janeiro: - Escola de Enfermagem Ana Neri, 1987, 15p. (Dissertaçāo de Mestrado).

14 MAR TINS, J.\& BICUDO, M.A.V. - A pesquisa qualitativa em psicologia: Fundomentos e recursos básicos. Moraes, São Paulo: 1989.

15 MAR TINS, J. et allii - A fenomenologia como alternativa metodológica para pesquisa. (No prelo da Revista de Enfermagem, São Paul).
16 MENEGHIM, P. AIDS: Assistência de enfermagem e revisăo de literatura. Rev. Paul. Enf., São Paulo: 6(3): 99-107, jul/set., 1986.

17 MORIYA, T.M. MANZOLI,M.C., Isolamento em doenças transmissiveis: conceituação em Enfermagem. Rev. Esc. Enf. - USP., São Paulo: 20(2): 89-100, 1986.

18 OLIVEIRA, M.H.P.; VIET TA,E.P.; MORIYA, T.M.; GIR, E. Reaçőes emocionais dos portadores de doenças sexualmente transmissiveis no momento da confirmação do seu diagnóstico, Rev. Bras. Ef., Braślia, 40(1), jan_f fev/mar., 1987.

19 PAS TERNAK, J. AIDS - Verdade e mito : historia e fatos, São Paulo: 159p. Círculo do Livro, 1988.

20 PRA TT, R.S. AIDS - Uma estratégia para a assistência de enfermagem, Sảo Paulo, Ática, 1986, 141p.

21 VERONESI, R.; FOCACCIA, R. AIDS entre profissionais de saúde: riscos e prevenção. Rev. Bras. de Cúnicas e Terapêuticas. XVIII (4): 130-132, Abril, 1989.

\begin{abstract}
ANEXO 1
Recomendações específicas pertinentes às rotinas e técnicas exigidas para a prevenção $e$ isolamento dos portadores de AIDS.

1. É usado dentro do sistema de isolamento uma

placa de fundo amarelo nas bordas, e no centro traz as precauções escritas em fundo branco, recomendando-se desta forma o isolamento protetor com precauções de fluidos $\mathrm{e}$ sangue:
\end{abstract}

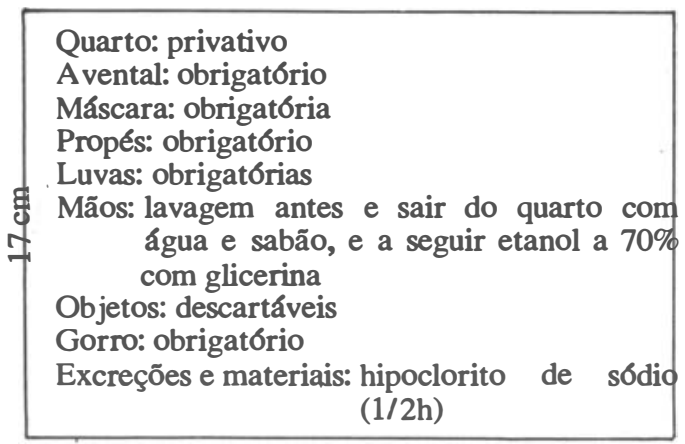

$23 \mathrm{~cm}$

2. Dentro do quarto: aparelho de pressão, estetoscópio, termômetro, colchão forrado de plástico.

3. Uso de 6culos protetores em casos de colheita de sangue arterial, aspiração de vias aéreas ou outros procedimentos com riscos.

4. Uso de objetos descartáveis: seringas, agulhas, copos, pratos, talheres, etc.

5. Não reencapar agulhas e escalpes.

6 Material cortante e seringas com sangue desprezar em galōes de plástico duro e com tampas.

7. Retirar roupa com técnica de saco duplo e em saco plástico de 100 litros.

8 Retirar material e lixo em saco plástico duplo.

9. Tubos, frascos, recipientes com material coletado (sangue, urina, fezes, escarro, liquor, material de biópsias): tampar e identificar com durex vermelho e transportar em caixa de aço inoxidável com tampa. Desinfetar a parte externa com álcool a 70\%.
10. Desinfecção de fluídos com solução de hipoclorito de sódio a $2 \%$ durante meia hora.

11. Limpeza de unidade com hipoclorito de sódio a $2 \%$. Enxaguar apos meia hora, pois o risco de oxidação e grande.

12. Propés usados - colocar em saco plástico separado dentro do saco de roupa.

13. Luvas usadas, sem sangue ou fluidos, colocar em galheteiro separado. Retirar em saco plástico, encaminhar à Central de Material.

14. Todo material do quarto - identificar com colante vermelho com as letras MC impressas (Material Contaminado).

15. Material usado de borracha - desprezar.

16. Material de aço inoxidável - encaminhar em saco plástico à Central de Material.

17. Material que não pode sof rer a ação do calor - usar solução de glutaraldeido durante meia hora. Enxaguar em água corrente com luvas. Se for necessário esterilização - deixar após por 10 horas. 
18. Material que não pode sofrer a ação do calor ou da solução de glutaraldeido - encaminhar à Central de Oxidoetileno.

19. Água para beber - usar frasco estéril de vidro.

20. Superfícies onde se derramar fluídos do pa- ciente - desinfetar com solução de hipoclorito de sodio a $2 \%$ forrar com papel e limpar apos 30 minutos.

21. Toda roupa que estiver no paciente deve estar livre de fluidos. Retirar logo, colocando no saco de roupa suja, se houver. 